\title{
¿Apelación del auto de apertura de juicio oral por la defensa? (Tribunal Constitucional)
}

\author{
Comentario de José Francisco Leyton Jiménez*
}

Santiago, 30 de diciembre de 2014.

(...)

\section{IGUALDAD ENTRE LOS LITIGANTES}

Decimosegundo: Que, asimismo, el requirente fundamenta la inaplicabilidad de los preceptos legales que ha solicitado, en que la aplicación de los mismos en la gestión judicial que se sigue, produciría una desigualdad entre los litigantes de la causa, el Ministerio Público, por una parte, y el acusado que deduce la inaplicabilidad, por otra;

Decimotercero: Que, efectivamente, el artículo 277 del Código Procesal Penal, en su inciso segundo, contempla únicamente el recurso de apelación contra el auto de apertura del juicio oral dictado por el juez de garantía, cuando lo interponga el Ministerio Público por exclusión de pruebas provenientes de actuaciones o diligencias declaradas nulas u obtenidas con inobservancia de garantías constitucionales, excluyendo en todo caso su interposición por otros intervinientes en el proceso penal, entre los cuales se encuentran los imputados;

Décimocuarto: Que, si bien la disposición legal antes citada restringe la interposición del recurso de apelación por parte del Ministerio Público solo a determinados supuestos, lo cierto es, conforme a jurisprudencia acompañada en autos y conocida por este Tribunal, que se ha admitido un recurso de apelación, deducido por el Ministerio Público, contra un auto de apertura de un juicio oral, cuando se había rechazado el informe pericial ofrecido por el mismo por idéntica razón a la que ahora tuvo en cuenta el juez de garantía para no admitir el informe ofrecido por el requirente de autos, esto es, por no acreditarse la idoneidad del perito. A tal efecto, la sentencia dictada por la Corte de Apelaciones de Santiago el 2 de septiembre de 2011, en causa Rol 1756-2011, acogió el recurso de apelación deducido por el Ministerio Público contra la resolución

* Abogado. Licenciado en Ciencias Jurídicas y Sociales de la Universidad de Chile. Magíster en Derecho Penal de la Universidad de Talca - Universitàt Pompeu Fabra; Magíster en Derecho de la Universidad de Chile. Profesor de Derecho Penal de la Universidad Diego Portales. Correo electrónico: jleyton@minpublico.cl 
del Juzgado de Garantía que había excluido la prueba pericial ofrecida por no haber acompañado los antecedentes demostrativos de la idoneidad del perito;

Decimoquinto: Que la llamada igualdad de armas, en materia de recursos, exige -salvo que haya una razón que lo justifique- que las distintas partes o intervinientes en un proceso tengan la misma posibilidad de impugnar las resoluciones que les perjudiquen, sobre todo si ellas inciden en un aspecto clave de un proceso, cual es la admisibilidad o la exclusión de ciertas pruebas;

Decimosexto: Que el precepto impugnado, como se ha señalado, establece una diferenciación entre el Ministerio Público y el imputado en relación a la apelación de la exclusión de prueba en el artículo 277 del Código Procesal Penal. Ante igual situación, la norma impugnada privilegia al persecutor público por sobre el imputado. Al primero se le concede el derecho a apelar, mas no al segundo. Este tratamiento diferenciado establecido por la ley es arbitrario y, por consiguiente, incompatible con el artículo 19, $\mathrm{N}^{\mathrm{o}} 2^{\circ}$, de la Constitución. No existe, como se verá, justificación razonable alguna que sustente la discriminación señalada;

Decimoséptimo: Que no cabe argumentar que a consecuencia de la diversidad de roles que en el proceso penal corresponden al Ministerio Público y al imputado, se justifique que frente a una exclusión de pruebas decretada por el juez de garantía solo el primero pueda apelar.

Es cierto que al Ministerio Público corresponde aportar las pruebas que demuestren la existencia del hecho punible y la culpabilidad del imputado, y que este bien pudiera adoptar una actitud pasiva, confiando en que el Ministerio Público no aporte las pruebas suficientes para condenarlo, pero esta posibilidad procesal no excluye el interés que tiene en poder aportar pruebas de descargo o exculpatorias que desvirtúen las que ha presentado el persecutor y de ello resulta que el Código Procesal Penal regule su presentación;

Decimoctavo: Que, en el caso que nos ocupa, estamos precisamente ante una prueba -un informe pericial- cuya producción pudiera llevar a conclusiones contrarias a las que se desprenden de los informes periciales tenidos en cuenta hasta ahora en el proceso, por lo cual resulta discriminatorio para el imputado cerrar la posibilidad de que la Corte de Apelaciones respectiva examine si la resolución del juez de garantía que rechazó el informe pericial ofrecido por no acreditarse la idoneidad del perito, se ajusta o no a derecho, siendo esta, precisamente, la consecuencia que trae la aplicación de los preceptos legales impugnados.

No es, en efecto, como lo sostiene el Ministerio Público, el artículo 316 del Código Procesal Penal -no impugnado por el requirente- el que le impide apelar, pues ello ocurre en virtud del artículo 277 del mismo Código, debiendo, en cambio, el citado artículo 316, tenerse en cuenta por la Corte de Apelaciones para decidir si la exclusión de la prueba pericial decretada por el juez de garantía se ajustó o no a derecho; 
Decimonoveno: Que no cabe argumentar que el Tribunal Constitucional, de acoger el requerimiento, esté creando un recurso que la legislación no contempla, pues lo cierto es que el recurso de apelación contra el auto de apertura del juicio oral existe, si bien su interposición está reservada en el artículo 277 del Código Procesal Penal a uno de los intervinientes y para ciertos supuestos, reserva y restricción que, de recibir aplicación el precepto legal impugnado en la gestión judicial que se sigue ante la Corte de Apelaciones de Concepción, produce una diferencia de trato carente de justificación y contraria a las garantías constitucionales de igualdad ante la ley y de igual protección de la ley en el ejercicio de sus derechos, que es motivo suficiente para acoger la inaplicabilidad solicitada;

Vigésimo: Que la existencia del recurso de nulidad, contemplado en el artículo 372 y siguientes del Código Procesal Penal, no es remedio suficiente para compensar la desigualdad entre el Ministerio Público y el imputado, que emana del artículo 277 del mismo cuerpo legal.

En efecto, dicho recurso se concede tanto para invalidar el juicio oral como la sentencia definitiva, o solo esta, entre otras causales, "[ $[$ c]uando en la tramitación del juicio o en el pronunciamiento de la sentencia, se hubieren infringido sustancialmente derechos o garantías asegurados por la Constitución o por los tratados internacionales ratificados por Chile que se encuentren vigentes" (artículo 373, letra a), del Código Procesal Penal);

Vigésimoprimero: Que, en efecto, si bien la existencia del recurso de nulidad no deja al imputado a quien se excluyó una prueba en el auto de apertura del juicio oral, en una situación de completa indefensión, lo cierto es que la interpretación que se ha dado a esta norma por los tribunales de justicia no garantiza la posibilidad de impugnación ante una exclusión de prueba, pues no corresponde a una doctrina admitida de modo uniforme y, además, no parece razonable dilatar para una parte -el imputado-, hasta el término del proceso, la corrección de una actuación judicial que puede dejarlo en indefensión, pudiéndose ella corregir prontamente mediante la vía de la apelación que los preceptos legales impugnados le cierran.

Y visto lo prescrito en los artículos $19, \mathrm{~N}^{\text {os }} 2^{\circ}$ y $3^{\circ}$, y 93, $\mathrm{N}^{\circ} 6$, e inciso decimoprimero, de la Constitución Política, así como en las disposiciones pertinentes de la Ley $\mathrm{N}^{\mathrm{o}}$ 17.997, Orgánica Constitucional del Tribunal Constitucional,

\section{SE RESUELVE:}

$1^{\circ}$. Que se acoge el requerimiento deducido a fojas $1 \mathrm{y}$, en consecuencia, las oraciones "...cuando lo interpusiere el ministerio público..." y “... de acuerdo a lo previsto en el inciso tercero del artículo precedente”, contenidas en el inciso segundo del artículo 277 del Código Procesal Penal, son inaplicables en los autos sobre recurso de hecho que se tramita ante la Corte de Apelaciones de Concepción bajo el Rol I.C. No 28-2014, por resultar contrarias a la Constitución. 


\section{Comentario}

La sentencia en comento se refiere a un caso en que fue discutida la restricción establecida en el Código Procesal Penal respecto del Recurso de Apelación del Auto de Apertura del Juicio Oral, siendo modificada, a mi juicio, erróneamente la jurisprudencia precedente a este respecto.

El asunto fue debatido en sede de inaplicabilidad ante el Tribunal Constitucional, siendo la norma impugnada el artículo 277 del Código Procesal Penal, en particular las oraciones ...cuando lo interpusiere el ministerio público... y ... de acuerdo a lo previsto en el inciso tercero del artículo precedente. El requiriente postulaba que dicha restricción vulneraba la Constitución Política en su artículo 19 , numerales $2^{\circ}$ y $3^{\circ}$, en tanto privilegiaría al Ministerio Público para recurrir de alzada en contra del auto de apertura en desmedro de la defensa, lo que generaría, a su entender, desigualdad de armas y desde allí, vulneración del ejercicio adecuado del derecho a defensa técnica. El voto de mayoría del fallo en comento siguió dicho razonamiento. Se estimó que la igualdad de armas exige entregar a los intervinientes las mismas herramientas impugnatorias respecto de las resoluciones judiciales que les causan agravio. En el caso analizado, la restricción de la apelación solo al persecutor penal público generaría un privilegio en desmedro del imputado, cuestión que, en palabras de la justicia constitucional, implica tratamiento diferenciado y arbitrario, incompatible con la preceptiva de la Carta Fundamental, no existiendo justificación razonable que sostenga dicha discriminación. El imputado podría tener interés en aportar pruebas de descargo o exculpatorias de la pretensión punitiva del Estado, cuya exclusión en la etapa procesal respectiva debería ser revisada en alzada mediante el recurso de estilo.

El fallo no da real alcance y sentido a una interpretación coherente de la norma impugnada con la sistemática que rige el proceso penal actualmente vigente en nuestro país. En efecto, las normas de los artículos 276 y 277 del Código Procesal Penal regulan la exclusión de la prueba que será conocida por el tribunal del fondo, en una audiencia especial, denominada de preparación de juicio oral. En caso de que el Juez de Garantía disponga allí la exclusión de pruebas obtenidas con infracción de garantías fundamentales o por medio de diligencias previamente declaradas nulas, se dispone el Recurso de Apelación solo de parte del Ministerio Público, el que es excepcional (la regla general es la negativa a conceder dicha impugnación en el sistema procesal penal); concedido en ambos efectos (368 CPP), con causales regladas, de derecho estricto y con peticiones concretas (artículo $367 \mathrm{CPP}$ ). Lo anterior, atendido el funcionamiento mismo del sistema, en que el juzgamiento es público, oral y basado en la inmediación, haciendo irreproducible en una eventual segunda instancia lo que allí sucede, con un Tribunal Oral provisto con las máximas garantías de imparcialidad y control, ajeno a todo prejuzgamiento del caso sometido a su conocimiento y decisión.

La exclusividad de la apelación del auto de apertura por el persecutor penal público descansa en antecedentes razonables y coherentes con la orgánica del sistema. En este sentido y como parte fundamental del debido proceso de derecho y recogido en el Pacto Internacional de Derechos Civiles y Políticos (artículo 14.2); la Convención Americana 
de Derechos Humanos (artículo 8.2); la Constitución Política (artículo 19, numeral $3^{\circ}$, en la voz "justo y racional procedimiento"), nuestro Código Procesal Penal, en su artículo $4^{\circ}$ reconoce una de las máximas fundantes en que descansa una política pública de persecución penal respetuosa de los derechos humanos: el principio o presunción de inocencia. Conforme a este, atendida la existencia de una notitia criminis, al justiciable se le presume inocente hasta que una sentencia ejecutoriada dictada por un tribunal letrado, imparcial y natural dictamine lo contrario. Ejerciendo el Ministerio Público del Estado una política pública de importancia, cual es, la persecución penal (artículo 83 $\mathrm{CPR}$; $1^{\circ} \mathrm{LOCMP}$; artículo $3^{\circ} \mathrm{CPP}$ ), sobre este recae el peso de vencer dicha presunción, señalando en su eventual acusación los medios probatorios de los que se valdrá para ello (artículo 259, literal f)) a efectos de lograr una sentencia condenatoria contra toda duda razonable (artículo $340 \mathrm{CPP}$ ). La persona acusada solo tiene que defenderse en el proceso penal, no teniendo el peso de presentar prueba alguna; mas, queriendo hacerlo, está facultado para ello en conformidad a la ley (artículo 295 CPP).

He ahí la razón de restringir la procedencia de la apelación del auto de apertura solo al persecutor penal público: sus deberes son precisos en torno a reunir prueba para acreditar su pretensión punitiva con respeto a las garantías fundamentales que informan los Tratados Internacionales y la Constitución, siendo el régimen recursivo por vía de apelación la forma en que el Tribunal de Alzada puede confirmar o desvirtuar que ha existido una vulneración en la obtención de las probanzas en perjuicio del imputado acusado. Así, el artículo 277 CPP es una norma de clara protección al justiciable, sistemática con el respeto al debido proceso, de derecho, permitiéndose incluso solicitar el sobreseimiento definitivo en el evento de que se deseche por parte del Juez de Garantía en esta etapa procesal, prueba estimada como imprescindible para acreditar el delito (artículo 277, inciso final CPP). Respecto del acusado, produciéndose una sentencia condenatoria con infracción a sus garantías, la legislación le entrega el sistema impugnatorio de nulidad a efectos de que un tribunal superior dictamine lo procedente conforme a derecho (artículo 373, literal a)). Es, a diferencia de lo señalado en el fallo, un remedio suficiente para resguardar actuaciones vulneratorias de los derechos del acusado.

El fallo constitucional comentado es erróneo en derecho: confunde la importancia de establecer un persecutor penal público, sobre el que descansa el deber de vencer la presunción de inocencia con pruebas respetuosas de las garantías fundamentales con los derechos que le asisten al imputado. Planteando un desequilibrio entre justiciable y Ministerio Público para tal efecto, entrega al primero un deber de generar prueba, cuestión que no contempla norma alguna del sistema, salvo como una facultad privativa.

No hay arbitrariedad en la comentada exclusividad recursiva, ya que descansa en argumentos de fondo que fundamentan la existencia del sistema procesal penal vigente, no siendo, por ende, una desigualdad contraria a la Carta Fundamental y menos, desproporcionada, ya que la exclusión de prueba es realizada por un Juez luego de una audiencia controvertida, en que la totalidad de los intervinientes puede plantear lo pertinente.

Finalmente, estimo que el Tribunal Constitucional en caso alguno puede tornarse en un nuevo legislador. A contrario de lo que razona en su considerando decimonoveno, el fallo en comento otorga a la defensa un recurso no contemplado en la ley, sobrepasando 
de esta forma sus atribuciones y generando una vulneración al Texto Fundamental, al arrogarse facultades que son propias del legislador de turno.

Es de esperar que, siguiendo el precedente al fallo en análisis (particularmente 2.354-12 TC y 2.320-12 TC) el Tribunal Constitucional retome una senda coherente con el sistema que busca defender. 